\title{
Interfaces entre Crítica Textual e Informática na edição de textos teatrais censurados
}

\author{
Interfaces between Textual Criticism and Computer Science in editing censored theatrical \\ texts
}

\author{
Isabela Santos de Almeida* \\ Universidade Federal da Babia, Salvador, Bahia, Brasil
}

\begin{abstract}
Resumo: No presente artigo, discorremos acerca das relações entre a Crítica Textual e a Informática, situando-as no campo dos estudos em Humanidades Digitais. A fim de refletir sobre tal questão, tomamos a prática de edição dos textos teatrais censurados de Jurema Penna para verificar algumas atualizações conceituais e metodológicas decorrentes desse contato disciplinar.
\end{abstract}

Palavras Chave: Humanidades Digitais. Crítica Textual. Textos teatrais censurados.

\begin{abstract}
In this article, we discuss the relations between Textual Criticism and Informatics, placing them in the field of Digital Humanities studies. In order to reflect on this issue, we took the practice of editing the theater censored texts of Jurema Penna to verify some conceptual and methodological updates resulting from this disciplinary contact.
\end{abstract}

Keywords: Digital Humanities. Textual Criticism. Theater censored texts.

\section{CONSIDERAÇÕES INICIAIS}

O trabalho de edição de textos, fundamentado no aparato teórico-metodológico da Crítica Textual, tem como principal propósito constituir um texto crítico, a partir de um ou de mais testemunhos, atualizando-o em sua materialidade física e linguística a fim de disponibilizá-lo para um público leitor. Nesse intento, a Equipe Textos Teatrais Censurados (ETTC/UFBA) tem se dedicado a editar e estudar os textos teatrais elaborados e encenados durante a ditatura militar, particularmente os produzidos na Bahia, preparando-os para a leitura e encenação. Este trabalho destaca-se por disponibilizar fontes para o estudo do teatro baiano, assim como é relevante para elucidar e elaborar os significados da ditadura militar, por meio dos estudos desenvolvidos acerca de aspectos linguísticos, literários e sóciohistóricos plasmados no texto.

Dar a ler tais documentos que registram a diversidade de fazeres teatrais na Bahia permite reconfigurar narrativas sobre o teatro baiano, identificar suas personagens, caracterizar seu público e delinear uma dramaturgia comprometida com a encenação, uma vez que sua escrita pressupunha a ação no palco. Santos (2012, p. 19-20) discute a importância desse trabalho, argumentando que

A inventariação, publicação e estudo de textos são um ato de preservação do patrimônio literário,
linguístico e escritural de determinada comunidade e constituem obrigação de arquivistas,
historiadores, e, particularmente, de filólogos, face às gerações vindouras, no sentido de
perpetuar a memória cultural, histórica, literária e linguística de um povo.

As edições preparadas pelos filólogos se constituem, necessariamente, a partir do estudo dos referidos objetos e, nesse sentido, também colaboram para propor diferentes caminhos interpretativos para os textos, na medida em que permitem compreender o

* Professora Adjunta do Departamento de Fundamentos para o Estudo das Letras, do Instituto de Letras/UFBA. Doutora em Literatura e Cultura (PPGLitC/UFBA). E-mail: isabelasa@ufba.br. 
contexto histórico de sua feitura, bem como de circulação e recepção pelos diferentes indivíduos e instituições, sejam eles promotores ou cerceadores das liberdades artísticas. A prática de edição dos textos teatrais censurados tem resultado em diversos produtos editoriais, a saber: edições críticas, interpretativas, sinópticas e fac-similares ${ }^{1}$. Boa parte dessas edições tem sido apresentada em meio digital, valendo-se das possibilidades engendradas por esse suporte, sobretudo em função de sua capacidade de dispor um grande volume de dados, de forma flexível e relacional, a um baixo custo.

Considerando as atualizações promovidas pela interação disciplinar entre a Crítica Textual e a Informática, no contexto das Humanidades Digitais, visamos, nesse artigo, elucidar algumas questões relativas a maneira como tal interface disciplinar promove atualizações conceituais e metodológicas que repercutem na prática editorial. Para tal propósito, tomaremos as edições dos textos teatrais censurados, desenvolvidas pela ETTC/UFBA, especificamente aquelas da dramaturga baiana Jurema Penna, a fim de ilustrar algumas questões.

\section{CRÍTICA TEXUAL E INFORMÁTICA: CRUZAMENTOS DISCIPLINARES}

As aproximações entre as tecnologias digitais e as Ciências Humanas, Letras e Artes têm provocado deslocamentos e ampliações nas concepções teóricas e metodológicas de diversas disciplinas. Se por um lado, a difusão dos computadores, tablets e smartphones tem feito emergir novos produtos que atestam a cultura e a escrita de uma sociedade atravessada pela existência no plano virtual; por outro, o desenvolvimento de novas tecnologias digitais fornece aos pesquisadores ferramentas para tratar e estudar os dados levantados. Emerge daí o conceito de Humanidades Digitais, que pode ser definido como

[...] the totality of the social sciences and humanities. The digital humanities are not tabula rasa. On the contrary, they rely on all the paradigms, savoir-faire and knowledge specific to these disciplines, while mobilizing the tools and unique perspectives enabled by digital technology.

3. The digital humanities designate a "transdiscipline", embodying all the methods, systems and heuristic perspectives linked to the digital within the fields of humanities and the social sciences ${ }^{2}$ (MANIFESTO, 2010, p.1)

Um dos pilares dessa proposta é a construção de um saber assinalado por um profundo do diálogo entre tradição e modernidade, a partir da combinação de metodologias consolidadas nas Ciências Humanas, Letras e Artes às inovações tecnológicas e renovações teóricas, explorando seus limites e possibilidades. Como se trata de um campo de estudos em constituição, torna-se fundamental para os pesquisadores das Humanidades Digitais realizar reflexões acerca do uso de tais tecnologias para a produção de novos conhecimentos. Nesse sentido, não é suficiente permanecer numa relação interdisciplinar, na qual cada uma das disciplinas continua na sua esfera mantendo contato apenas pontual. Ao contrário, fazse necessário ampliar tal perspectiva, considerando suas implicações para as questões relativas ao convívio social, patrimônio e herança cultural, produção, divulgação e circulação do conhecimento, dentre outras, uma vez que estas tecnologias constituem meios pelos quais a humanidade interage e constrói bens materiais e visões de mundo.

\footnotetext{
${ }_{1}^{1}$ Para conhecer os trabalhos desenvolvidos pela ETTC, recomenda-se o acesso ao site www.textoecensura.ufba.br. 2 “[...] a totalidade das Ciências Sociais e Humanidades. As Humanidades Digitais não são tabula rasa. Pelo contrário, elas apoiam-se em todos os paradigmas, savoir-faire e conhecimentos específicos dessas disciplinas, mobilizando as ferramentas e perspectivas permitidas pela tecnologia digital. 3. As Humanidades Digitais designam uma "transdisciplina", que incorpora todos os métodos, sistemas e perspectivas heurísticas relacionadas ao digital nos domínios das Humanidades e Ciências Sociais”. (MANIFESTO, 2010, p.1, tradução nossa).
} 
Nesse sentido, um estudo na área das Humanidades Digitais contemplaria uma produção de conhecimento transdisciplinar. Dentre as diversas acepções para o termo transdiciplinaridade, é possível defini-lo como

um tipo de interdisciplinaridade em que as fronteiras entre as disciplinas envolvidas são superadas, gerando-se uma integração de seus diversos conceitos e metodologias. Aqui, o prefixo trans se refere justamente à possibilidade de ultrapassar as fronteiras disciplinares, em direção a uma abordagem unificada que seja capaz não só de articular harmoniosamente as contribuições das diversas disciplinas, mas também de iluminar retroativamente os conceitos e metodologias de cada uma delas. (PINTO, 2005, p. 154-155)

Não se trata de permanecer na esfera da interdisciplinaridade, em que existem intercâmbios e enriquecimentos entre as disciplinas, a proposta avança da interação para a integração. $\mathrm{Na}$ perspectiva transdisciplinar, constitui-se um novo campo de pesquisa que implica em efetivos deslocamentos teóricos e metodológicos, estabelecendo novas formas de pensar o objeto de estudo, bem como novas maneiras de abordá-lo. Ilustram uma produção transdisciplinar, como proposto pelas Humanidades Digitais, as novas textualidades virtuais, nas quais estão empenhados designers, produtores, programadores e escritores, todos imbuídos do objetivo de elaborar um outro tipo de livro que promova inovações no suporte de leitura, deslocando, por exemplo, o conceito de livro impresso e livro virtual.

O aplicativo The silent history, disponível para o sistema operacional IOS, via download na App Store, trata-se de uma narrativa que conta a história de crianças desprovidas de habilidades linguísticas e as suas consequentes dificuldades de interação social. Apesar de ser categorizado no gênero romance, o e-book não possui uma autoria convencional, a responsabilidade da criação é atribuída a Ying, Horowitz \& Quinn LLC, empresa que reúne os idealizadores e executores do aplicativo, que, além de um escritor para o texto literário, inclui especialistas em design e programação. Esta integração entre diferentes profissionais na produção de novas formas para o romance exemplifica as atividades na área de Humanidade Digitais, uma vez que, nesse caso, a composição de um livro digital não se restringiu a transpor o texto do suporte papel para o meio virtual, mas empenhar conhecimentos, teorias e metodologias a fim de construir novos formatos e funcionalidades para o texto em meio virtual, explorando os recursos disponíveis.

Ao leitor desse livro digital diferentes desafios são propostos, por exemplo, seu conteúdo é disponibilizado por partes, e não integralmente, e em alguns países, é possível baixar capítulos específicos disponibilizados em diferentes espaços de uma determinada cidade, demandando que o leitor se desloque para ter acesso a certo conteúdo. A partir desse exemplo, é possível verificar que "[a] revolução do texto eletrônico é, de fato, ao mesmo tempo, uma revolução da técnica de produção dos textos, uma revolução do suporte escrito e uma revolução das práticas de leitura" (CHARTIER, 2002, p. 113). Disto resulta que a interação disciplinar entre Crítica Textual e Informática se dá tanto a partir das características próprias do suporte digital, tais como sua flexibilidade, capacidade de integração e hipermidialidade, quanto a partir dos conceitos oriundos das tecnologias digitais, como linguagem de programação, hipertexto, links, dentre outros.

Os estudos em Crítica Textual frequentemente se constituem no âmbito transdisciplinar, uma vez que o trabalho editorial demanda conhecimento das mais diversificadas áreas. No que se refere aos textos antigos e medievais, os aportes teóricometodológicos da paleografia, diplomática, codicologia fazem-se fundamentais para adentrar o sistema de signos dispostos nos manuscritos. Para a edição de textos impressos, deve-se apropriar-se dos conhecimentos da bibliografia material (CAMBRAIA, 2005). No caso dos manuscritos autógrafos, o contato com os estudos de gênese possibilitou uma renovação nas práticas editoriais, permitindo compreender o texto em seu processo de elaboração. 
Independente das características do objeto de estudo, se textos antigos e medievais ou se textos modernos e contemporâneos, é possível desenvolver edições valendo-se da transdiciplinaridade entre Crítica Textual e Informática. Veja-se, a proposta de The Homer Multitext (DUÉ; EBBOTT, 2009), na qual os editores se utilizam da flexibilidade do meio digital para apresentar a movência dos textos atribuídos a Homero. Tendo em vista seu caráter profundamente vinculado à tradição oral e à performance, emerge a impossibilidade de se escolher uma única lição, optando-se por dispor de todas elas para o leitor, nesse sentido, os editores apresentam os testemunhos integralmente, bem como disponibilizam ferramentas que permitem sua comparação.

Outra iniciativa exemplar da interlocução disciplinar entre Crítica Textual e Informática encontra-se no trabalho desenvolvido pela equipe do The William Black Archive. As obras de William Blake foram impressas pelo próprio autor, utilizando-se de uma técnica de impressão por corrosão de chapas metálicas que reproduziam texto e imagem ao mesmo tempo. As inúmeras edições destas obras foram, no entanto, frequentemente orientadas a partir de uma perspectiva de valorização do texto verbal em detrimento do texto não-verbal. As justificativas para a edição apenas da parte verbal, em geral, centram-se no alto custo de uma edição em papel especial, com impressão em cores. A construção do arquivo hipertextual para a referida obra permitiu, assim, restituir aspectos de sua textualidade, fundamentais para a compreensão do texto (PORTELA, 2015; LOURENÇO, 2009).

Nesse sentido, em ambas as situações acima citadas, o texto em suporte digital permite reconsiderar as possibilidades de significação já presentes nos textos de partida ou, ainda, decorrentes de sua circulação e recepção, que, no entanto, foram escamoteadas pelo caráter bidimensional das edições impressas. A respeito dos textos atribuídos a Homero, a possibilidade de representar um multitex to coaduna com a característica da própria obra, um texto elaborado no plano da oralidade e a partir de suas diversas performances, para a qual não se pode falar em intenção autoral ou variantes, visto que não há um original que lhe sirva de parâmetro. No segundo caso, é possível evidenciar aspectos da multimodalidade do texto de Blake, a partir da criação de fac-símiles digitais, abrindo espaço para que texto verbal e imagético sejam lidos como uma unidade, evidenciando, portanto, o caráter do escritorpintor (PORTELA, 2015).

Tais experiências editoriais confirmam aquilo que McGann elucidou, nos anos 1990, acerca dos usos do meio virtual na proposição de edições, nomeando-as como hiperedições:

The electronic environment of hyperEditing frees one to a considerable extent from these codex-based limits. Indeed, computerization for the first time releases the logical categories of traditional critical editing to function at more optimal levels. [...] To function in a "hyper" mode, an editing project must use computerization as a means to secure freedom from the analytic limits of hardcopy text. ${ }^{3}$ (McGANN, 1995, p. 3).

O suporte digital como ferramenta de experimentação permite ao pesquisador levar seu objeto a suplantar a forma material do livro e, a partir de então, dotar a edição de possibilidades que estariam engessadas pelo formato do impresso.

Dentre as emancipações que o suporte virtual confere aos projetos editoriais está o vasto espaço disponível para apresentar as edições em múltiplos linkes e janelas. O editor pode escolher, então, disponibilizar várias propostas de edição para um mesmo texto, de maneira a oferecer edições direcionadas a especialistas ou leigos, destinadas ao estudo da língua do texto ou das representações que ali se apresentam. Todos esses materiais estariam reunidos em um arquivo. Conforme afirma Morrás (2003, p. 5),

3 "O ambiente eletrônico de hiperedição liberta-nos, em grande medida, destes limites baseados no códice. Na verdade, a informatização, pela primeira vez, libera as categorias lógicas de edição crítica tradicional para funcionar em níveis mais otimizados. [...] Para funcionar em um modo de "hiper", um projeto de edição deve usar a informatização como um meio para garantir a liberdade dos limites analíticos do texto impresso" (MCGANN, 1995, p.3, tradução nossa). 
El archivo electrónico de textos permitirá así superar la dicotomía que enfrenta a editores conservadores o documentalistas e intervencionistas o idealistas [...] reuniendo en un archivo electrónico la edición crítica, las versiones que pueda haber, las transcripciones de cada uno de los textos y su reproducción facsimilar. ${ }^{4}$

O suporte digital permite ao filólogo apresentar os diferentes tipos de edição, podendo estas servir a pesquisadores de muitas especialidades, bem como ao público não especializado. Além disso, devido ao alto custo das edições impressas mais completas, contendo as diversas versões e os fac-símiles, torna-se difícil publicá-las em suporte papel. Vale ressaltar que disponibilizar a massa documental oriunda da recensio e os diferentes tipos de edição, em suporte virtual, não é suficiente, fazendo-se necessário organizá-la, conforme os propósitos editoriais. A estrutura da edição em meio digital, dessa forma, deve orientar o leitor na exploração do ambiente virtual, a fim de que se possa dispor de uma referência para se navegar por ela.

Além disso, a flexibilidade do suporte digital permite que diferentes produtos editoriais sejam adicionados ao longo do tempo, não havendo necessidade de se publicar apenas o produto final, sendo possível apresentar as diferentes propostas editoriais como resultados parciais de uma pesquisa, conforme descrição da constituição do William Blake Archive,

The William Blake Archive tem funcionado com uma tripla lógica: uma lógica de acreção, segundo a qual novos textos e imagens se acrescentam periodicamente aos já existentes; uma lógica de ramificação, segundo a qual os textos e imagens acrescentados vão abrindo novos ramos dentro do arquivo [...]; uma lógica de revisão, segundo a qual certos parâmetros de codificação são revistos de acordo com o surgimento de novas ferramentas e normas técnicas [...] (PORTELA, 2015, p. 21).

Por se tratar de um trabalho minucioso, a maleabilidade do suporte digital permite que os projetos editoriais sejam construídos na lógica da adição de novas informações, resultando em um produto editorial mais complexo, completo e ramificado. Some-se a isso a necessidade de frequente revisão das técnicas empregadas para desenvolver o arquivo digital, tendo em vista a necessidade de torná-lo adequado às mudanças da tecnologia. Nesse cruzamento disciplinar, é, portanto, possível ampliar as dimensões do trabalho editorial, adaptando-o ao contexto tecnológico do seu tempo, no intuito de potencializar os resultados, qual sejam, editar e divulgar as produções escritas de uma sociedade. Abordaremos, em sequência, algumas questões relativas a essa interface disciplinar que se apresentam na prática de edição de textos teatrais censurados para o suporte digital.

\section{ASPECTOS DA EDIÇÃO DE TEXTOS TEATRAIS CENSURADOS EM MEIO DIGITAL}

A partir de Cerquiglini (2000, p.5), entendemos que os contatos disciplinares entre a informática e os estudos filológicos desencadeiam três consequências principais, assim,

[l'informatique contemporaine] nous fournit, tout d'abord, des instruments d'édition nouveaux (ordinateurs multimédias, réseau de l'internet, etc.) ; elle nous munit ensuite de concepts et d'idées (notion d'hypertexte, de texte malléable, de partage textuel) qui changent notre image du texte; elle marque enfin, et surtout, la fin du monopole livresque comme support de l'écrit. ${ }^{5}$

\footnotetext{
4 "O arquivo eletrônico de textos permitirá, assim, superar a dicotomia que os editores conservadores ou documentalista e intervencionistas ou idealistas enfrentam, reunindo em um arquivo eletrônico a edição crítica, as versões que possam existir, as transcrições década um dos textos e sua reprodução fac-similar." (MORRÁS, 2003, p.3, tradução nossa)

5 "[a informática contemporânea] nos fornece, em primeiro lugar, novas ferramentas de edição (computadores multimídia, rede de internet, etc.); ela irá nos munir de conceitos e ideias (noção de hipertexto, texto maleável, de compartilhamento de
} 
Na presente seção, nos propomos a elucidar, a partir de experiências de edição em meio digital desenvolvidas com os textos teatrais de Jurema Penna, aspectos da interlocução entre Crítica Textual e Informática, considerando os novos instrumentos de edição, as ampliações promovidas ao conceito de texto, bem como da emergência de novos suportes de escrita.

O primeiro desses aspectos também parece ser o mais evidente e capaz de evocar a própria noção de tecnologia: nos referimos aos hardwares e softwares que viabilizam o trabalho editorial. No que tange à elaboração da edição, verificamos que as etapas mais mecânicas do processo editorial, tais como a transcrição, a collatio e a constitutio textos, podem ser agilizadas com o uso de programas de computador. A informatização dessas etapas também evita os erros humanos, sobretudo aqueles erros de cópia, no momento da transcrição, ou os erros de identificação das modificações textuais. Por sua vez, o uso de softwares para apresentação da edição permite ao editor dedicar mais tempo para a preparação do texto crítico e do aparato, uma vez que o programa cuida da disposição desses elementos na tela. Com a automatização dessas etapas, é possível realizar edições de forma mais célere, bem como investir mais tempo nas etapas interpretativas.

Mesas digitalizadoras, scaneres, máquinas fotográficas e programas de edição de imagens, em geral, são utilizados no processo de recolha dos textos teatrais censurados. Procedemos à digitalização desses textos, tendo como principal objetivo facilitar o acesso aos documentos, por meio da posterior difusão do documento digital, evitando, por consequência, o contato com o original e as deteriorizações ao suporte decorrentes de seu manuseio. Softwares de edição de imagens são utilizados quando necessário para solucionar algum problema de digitalização, como da angulação da fotografia, ou correção da iluminação.

Considerando que os textos teatrais censurados são datiloscritos, portanto trazem um tipo muito semelhante ao usado em fontes de computador, bem como apresentam um bom estado de conservação, o uso de programas de leitura de caracteres ópticos mostrou-se eficaz. A transcrição dos textos pode ser realizada por meio de diversos programas encontrados gratuitamente na Internet, nesse caso, utilizamos o Free On line OCR que apresentou uma bom nível de acurácia na identificação dos caracteres, agilizando o processo de transcrição do texto. O uso do software, no entanto, não dispensa a cuidadosa revisão do editor, mas evita que equívocos de cópia sejam inseridos, já que o problemas provocados pelo OCR são muito prototípicos e reconhecíveis, como por exemplo "cl,e", em vez de "de", erro ao ler diacríticos, que ora são reconhecidos como um número, como " $5 \mathrm{v} 6$ ", em lugar de "avó", ora como uma letra maiúscula, como em "negOcio".

No caso dos textos de tradição politestemunal, o processo de colação também pode ser realizados por meio de softwares específicos, desenvolvidos por centros de pesquisa em Humanidades Digitais, como o CollateX, o Juxta Commons e o Versioning Machine. O CollateX é uma ferramenta que compara diferentes versões de um texto a partir do princípio da tokenização. Neste, o texto é subdividido em partes que são comparadas e alinhadas, o que permite observar não apenas acréscimos e supressões, mas também deslocamentos. Apesar de sua eficiência na colação, o software não apresenta uma interface gráfica, o que exige do usuário conhecimentos mais avançados de linguagem de programação. $\mathrm{O}$ Collate $X$ dispõe dos seguintes formatos de saída: Java, TEI, XML, GraphML, GraphViz DOT, demandando outras aplicações para visualizar os resultados da colação, visto que a exibição desses reultados não é o objetivo do software.

O Juxta Commons também realiza a colação entre os diferentes testemunhos e permite exportar, em arquivo .txt ou .doc, o resultado dessa etapa, dispondo das modificações

texto) que mudam a nossa imagem do texto; ela marca, por último, mas não menos importante, o fim do monopólio livresco como suporte da palavra escrita." (CERQUIGLINI, 2000, p.5, tradução nossa). 
textuais de um testemunho ao outro, dados que comporão o aparato de uma edição crítica. Permite também exportar o resultado da colação nos parâmetros do XML definidos pela Text Encoding Initiative ${ }^{6}$. Além disso, traz alguns tipos de visualização da colação, como o modo side-by-side, em que as versões são justapostas na tela ou o modo heat map no qual o usuário pode selecionar o texto que será tomado como referência para a colação.

Considerando o fácil acesso, a interface amigável, a disponibilidade de diferentes tipos de visualização dos resultados da colação e o recurso de adicionar notas explicativas ao logo do texto, optamos pelo Juxta Commons para a colação das diferentes versões dos textos teatrais censurados e apresentação de uma edição sinóptica. Por se tratar de uma aplicação para Web, o referido software apresenta lentidão no processamento dos dados e tem a desvantagem de permitir a visualização lado a lado de apenas dois testemunhos por vez.

O Versioning Machine, por sua vez, soma-se aos softwares que além de possibilitar a colação entre as versões de um mesmo texto, disponibiliza uma interface para a apresentação dessa colação. Esse aplicativo mostra-se especialmente interessante para a edição de textos teatrais censurados, pois permite o inserção de material multimídia, como links, sons, imagens e vídeos, além da vantagem de se adicionar notas. Tais recursos permitem a apresentação dos fac-símiles dos textos teatrais censurados junto à edição, bem como o acréscimo de referências feitas no texto do espetáculo, configurando outras possibilidades para a construção de notas explicativas do editor.

Note-se que os recursos apresentados pelos softwares aqui, brevemente, listados resultam em uma edição semelhante ao tipo sinóptico, na qual é possível "demonstrar pontos em que tais versões se aproximam ou se afastam, trazendo notas e comentários que visam esclarecer os textos em seus múltiplos aspectos" (BORGES; SOUZA, 2012, p. 38). Na figura 1, apresentamos a edição sinóptica para Babia Livre Exportação ${ }^{7}$, elaborada e apresentada pelo Juxta Commons. A edição traz as duas versões do texto, lado a lado, no modo side-by-side, e está acompanhada dos comentários da editora, apenas disponível no modo de visualização heat map.

Figura 1 - Edição sinóptica para Bahia Livre Exportação



Fonte: Almeida, 2014

Se nas edições, em meio digital, do tipo sinóptica o editor se concentra em propor comentários, esclarecimentos e dispor informações paratextuais concorrendo para o entendimento do texto, nas edições críticas em meio digital mais trabalho deverá ser dispensado para a elaboração de uma arquitetura capaz de, por um lado apresentar um texto crítico, e por outro manter nessa apresentação a diversidade de versões, evidenciando a história da tradição de um texto, os atores sociais implicados na sua disseminação, as formas

\footnotetext{
${ }^{6}$ Padrão para codificação de textos em formato XML, amplamente utilizado por universidades, bibliotecas e projetos de edição de textos.

${ }^{7}$ Babia Livre Exportação, da dramaturga baiana Jurema Penna, foi escrito e encenado nos anos de 1975 e 1976, em Salvador$\mathrm{Ba}$, legando duas versões diferentes do texto. A peça narra a história da Bahia, desde a colonização até os dias atuais. A edição em suporte digital que apresentamos compõe a tese de doutorado desta pesquisadora.
} 
materiais assumidas, assim como as leituras elaboradas pelos contemporâneos a partir das possibilidades do suporte digital.

Para a construção de uma edição em meio digital, no entanto, não basta a simples transposição da lógica do texto impresso para o texto virtual. Ao contrário, é preciso compreender aspectos próprios do suporte digital, entendendo as diferentes codificações de dados que subjazem à interface desses objetos digitais, camada superficial e acessível, escrita em uma linguagem humana que permite ao leitor mover-se. Tomaremos a definição de Paixão de Souza acerca do texto digital, segundo a qual trata-se de um

texto cujo processo de difusão envolve a codificação de informação por linguagens artificiais, e que se constitui materialmente como informação linguística codificada matematicamente e apresentada com a forma de escrita humanamente legível. (PAIXÃO DE SOUSA, 2009, p.173)

A aparência que o texto digital adquire na tela decorre, dessa forma, dos inúmeros parâmetros de sua apresentação, bem como, de um lado, dos programas utilizados na compilação desses parâmetros, e de outro lado, dos diferentes hardwares e softwares utilizados pelo leitor na navegação desses textos. Para o leitor não especializado, a linguagem artificial utilizada na codificação dos dados é imperceptível, uma vez que se encontra disfarçada por uma interface elaborada em função da similitude dos impressos. A página em branco de editores de texto, como o Microsoft $W$ ord, reforça essa identidade entre os impressos e os virtuais, que só é abalada quando um erro de codificação, tais como a incompatibilidade entre versões de programas, torna visível o código-fonte (PAIXÃO DE SOUSA, 2009).

A diversidade de textos digitais instaura, assim, diferentes níveis de "ocultação" da linguagem de programação e para melhor compreendê-la, Paixão de Sousa (2009) propõe uma tipologia dessas produções. O primeiro tipo são aqueles cuja a produção e a recepção se dão em meio digital; deste grupo fazem parte os textos em formato HTML (HyperText Markup Language), o XML (eXtensible Markup Language) e o XHTML (eXtensible HyperText Markup Language) e tem como seu principal representante o hipertexto. Esta categoria traz para o leitor uma relação menos opaca entre a interface e a linguagem de programação que a sustenta, tais textos podem ser lidos por programas amplamente conhecidos, como os navegadores. Esta transparência entre interface e código resulta na constituição de um sistema aberto, modificável e atualizável.

O segundo tipo é construído com os usos de ferramentas digitais, mas sua circulação será feita em suporte papel. Nesta categoria, Paixão e Souza (2009) relaciona os formatos .doc, .odt, .pdf, dentre outros constituídos conforme a lógica do impresso. Sobre as consequências da escolha desses formatos, a pesquisadora destaca a dependência deles em relação ao software em que foram produzidos, bem como às prováveis perdas de dados decorrentes de sua atualização.

Tendo em vista os aspectos técnicos relativos ao hipertexto, é preciso reconhecer que a materialidade digital irá repercutir na noção de texto adotada pelo editor, no que tange a sua representação na tela e ao seu caráter móvel, hipermidiático e relacional. O hipertexto configura-se como uma técnica da escrita característica do suporte digital, sobretudo da Web, visto que permite vincular diferentes documentos ou partes de um mesmo documento, a diferentes mídias, por meio de hiperlinks. Considerando os espaços virtuais para os quais o leitor é remetido ao ler um hipertexto, Bolter (2001, p.45) entende a escrita hipertextual como uma escrita espacial, nesse termos,

Hypertext such as the World Wide Web refashion the voice of the text as we have known it in print and in earlier technologies of writing; they turn vocal writing into spatial writing. The excitement and immediacy of the text is no longer an aural experience, as it was when texts were in manuscripts and as it has remained, however, muted, in printed book. Instead, the World Wide Web offers us the experience of moving through a visual and conceptual space different 
from the space of the book, although this experience still depends on our intuitive understanding of that earlier writing space. Indeed, we depended in a variety of ways on our knowledge of print in order to read and write hypertexts. ${ }^{8}$

Muitos desses espaços, no entanto, já estão presentes no livro impresso, em formato de notas de rodapés, índices, sumários, referências e remissões. O hipertexto, portanto, atualiza para um novo suporte estruturas já existentes, promovendo, nesse processo uma ressignificação das suas possibilidades de representação. Faz-se necessário, então, ampliar os sentidos de texto, superando as noções associadas tanto à lineridade de suas formas, quanto a sua função de repositório de idéias e sentidos. Para tanto, recorremos à discussão desenvolvida por McKenzie (2005, p. 69), segundo a qual texto pode evocar dois principais sentidos:

$[u]$ no es el texto sancionado por un autor fijo e históricamente definible. El otro es el texto como algo siempre inconcluso, por tanto, abierto, variable, sujeto a un perpetuo rehacerse por parte de sus lectores, sus ejecutantes o sus espectadores. ${ }^{?}$

Na primeira definição, o autor ocupa o papel de organizador dos sentidos do texto, é ele quem autoriza ou desautoriza certas leituras, impondo-se como figura legitimadora de um discurso. A segunda acepção se caracteriza por compreender a incompletude como algo inerente ao texto, uma vez que o seu sentido será construído apenas no momento em que o público lhe atribuir significados. Passamos, portanto a entendê-lo como uma construção sócio-histórica, elaborada a partir de interações entre sujeitos sociais, condicionada pelas tecnologias disponíveis em seu tempo e pelas formas materiais que assume.

Sendo o hipertexto uma tecnologia de escrita, seu caráter hipermidiático emerge como principal diferença em relação aos manuscritos e impressos, visto que coaduna diferentes linguagens, incluindo textos verbais, documentos sonoros e pictóricos, além de audiovisuais à distância de um click. Tal noção de hipermídia conflui com a ampliação nos sentidos de textos apresentada por McKenzie

Entiendo por «textos» los datos verbales, visuales, orales y numéricos en forma de mapas, impresos y música, archivos de registros sonoros, de películas, vídeos y la información computarizada; de hecho, todo desde la epigrafía a las últimas formas de discografía. No es posible ignorar el reto que suponen esas nuevas formas. (McKENZIE, 2005, p. 30) ${ }^{10}$

A noção de texto tem o seu sentido expandido, não se restringe mais ao verbal em sua modalidade escrita, mas congrega as produções compostas em um sistema de signos, parte de uma cultura, que seja capaz de produzir sentidos ao integrar-se a outros sistemas. Ao se pensar nas novas tecnologias e as formas como elas se relacionam à cultura escrita, McKenzie reitera os desafios intrínsecos à compreensão de tais materialidades e ao entendimento das especificidades de cada linguagem em que estas produções são elaboradas.

\footnotetext{
8 "O hipertexto, assim como a World Wide Web, remodela a voz do texto como a conhecemos nos textos impressos e nas primeiras tecnologias da escrita para Web; elas transformam a escrita vocal em escrita espacial. A emoção e imediatismo do texto não é mais uma experiência sonora, assim como era quando os textos estavam em manuscritos e que permaneceu, no entanto, silenciado, no livro impresso. Em vez disso, a World Wide Web nos oferece a experiência de mover-se através de um espaço visual e conceptual diferente do espaço do livro, muito embora essa experiência ainda dependa da nossa compreensão intuitiva desse espaço de escrita anterior. $\mathrm{Na}$ verdade, dependemos de muitas de maneiras do nosso conhecimento do texto impresso, a fim de ler e escrever hipertextos.” (BOLTER, 2001, p. 45, tradução nossa).

9 "Um é o texto legitimado por um autor fixo e historicamente definível. O outro é o texto como algo sempre inconcluso, portanto, aberto, variável, sujeito a um perpétuo refazer-se por parte de seus leitores, seus intérpretes ou seus espectadores" (MCKENZIE, 2005, p.69, tradução nossa)

10 'Entendo por 'textos' os dados verbais, visuais, orais e numéricos, em forma de mapas, impressos e música, arquivos de registros sonoros, filmes, vídeos e a informação computadorizada; de fato, tudo desde a epigrafia às últimas formas de discografia. Não é possível ignorar o desafio que supõe estas novas formas (MCKENZIE, 2005, p. 30, tradução nossa).
} 
Acerca da diferença das linguagens trazidas pelos textos sonoros, fílmicos, digitais, dentre outros, em contraste com a linguagem verbal, Chartier $(2005$, p.7) afirma que

[...] hay textos que no suponen utilización alguna del lenguaje verbal: la imagen, el mapa, la partitura, el territorio mismo cuando los hombres le otorgan significados, deben ser tenidos por textos «no verbales». Lo que permite designarlos así es el hecho de que todas esas producciones simbólicas han sido construidas a partir de relaciones entre signos que forman un sistema y cuyo sentido es definido por convención. ${ }^{11}$

Esta ampliação de sentido torna-se fundamental para a edição de textos teatrais, uma vez que estes são atravessados por uma série de outros dados verbais, auditivos e visuais. Músicas, efeitos sonoros e de iluminação, além de figurino, cenário e o próprio espaço cênico configuram-se como textos que são entrelaçados na formulação do espetáculo.

As fotografias das peças, por sua vez, também desempenham um papel importante para a construção dos sentidos do texto teatral censurado, uma vez compreendidas como textos não verbais, torna-se relevante estabelecer o cotejo entre as informações ali presentes e o texto do espetáculo. Em Babia Livre Exportação, as rubricas indicam a expressão corporal dos atores na cena, informação essa que pode ser suplementada pela fotografia da cena publicada na reportagem do Jornal Tribuna da Bahia, em julho de 1975, (cf. fig.2) nesta cena é possível ver muitos atores no chão e um ator em um plano superior vestido de camisa, calça e chapéu.

Figura 2 - Fotografia da cena de Babia Livre Exportação

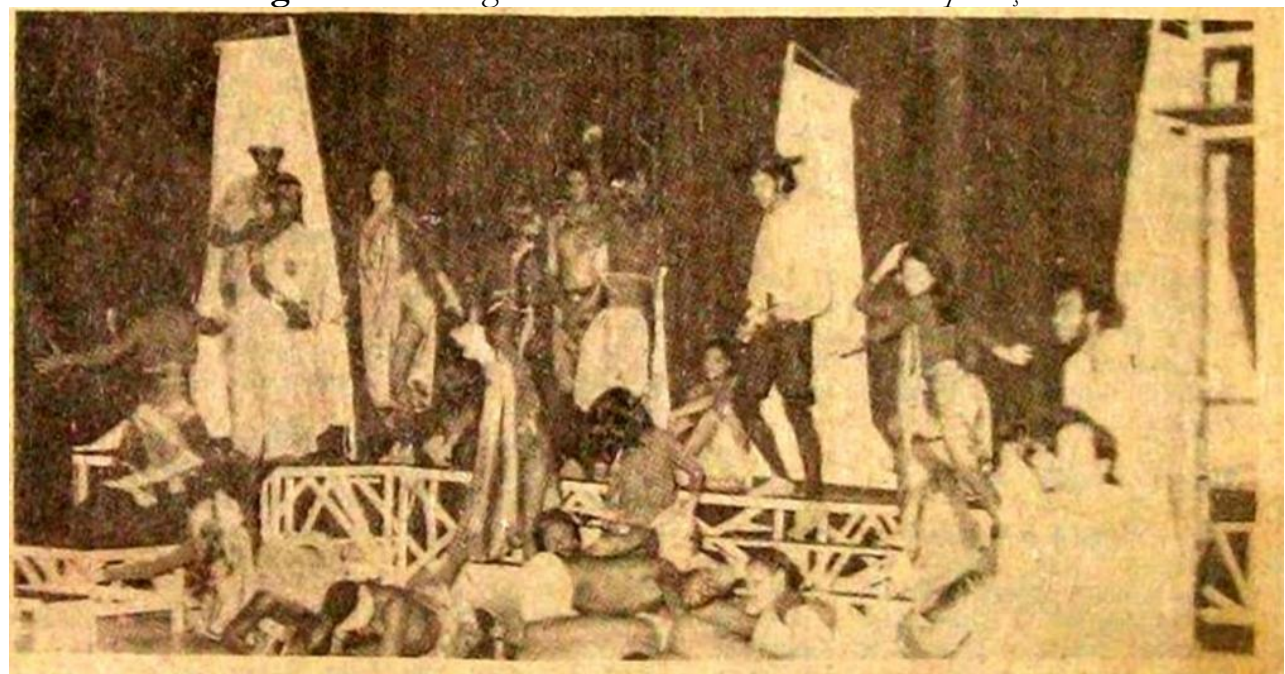

Fonte: Jornal Tribuna da Bahia, 22 jul. 1975.

A partir da análise do scripte da figura 2, podemos identificar a cena representada com o trecho transcrito em sequência, identificando a personagem de camisa, calça e chapéu com o feitor e os demais seminus no chão como os negros humilhados por ele:

FOLCLORE - (Candomblé. Baixam três "santos". A CENA É INTERROMPIDA COM A ABRUPTA ENTRADA DO FEITOR).

FEITOR - Para com essa porcaria cambada de negro pagão! Para! Para! Feiticeiros! Macumbeiros! Para...

(Eles param atemorizados. A mãe de santo "desincorpora" os manifestados)

(PENNA, 2014, f. 6)

\footnotetext{
11 “[...] há textos que não supõem a utilização alguma da linguagem verbal: a imagem, o mapa, a partitura, o próprio território, quando os homens lhe outorgam significados, devem ser compreendidos com os textos 'não verbais'. O que permite designá-los assim é o fato de que todas essas produções simbólicas foram construídas a partir de relações entre signos que formam um sistema e cujo sentido é definido por convenção (CHARTIER, 2005, p.7, tradução nossa).
} 
Na edição crítica realizada em meio digital para o texto Babia Livre Exportação, optamos por dispor as imagens em aparatos, com o uso do recurso tooltip, com o qual ao se passar o cursor sobre uma palavra marcada com hiperlink abre-se, na mesma janela, uma caixa com as informações do aparato, que podem conter notas, registro das modificações textuais das diferentes versões, bem como, nesse caso, recursos audiovisuais e links externos à edição (Cf. fig. 3). Reproduzimos a reportagem integralmente como nota explicativa no início da edição, visto que por meio da leitura da mesma, é possível ter informações acerca do contexto de encenação e da composição da cena, bem como aspectos da recepção do espetáculo, que podem orientar a leitura do texto em questão.

Figura 3 - Aparato de notas da edição crítica de Babia Livre Exportação

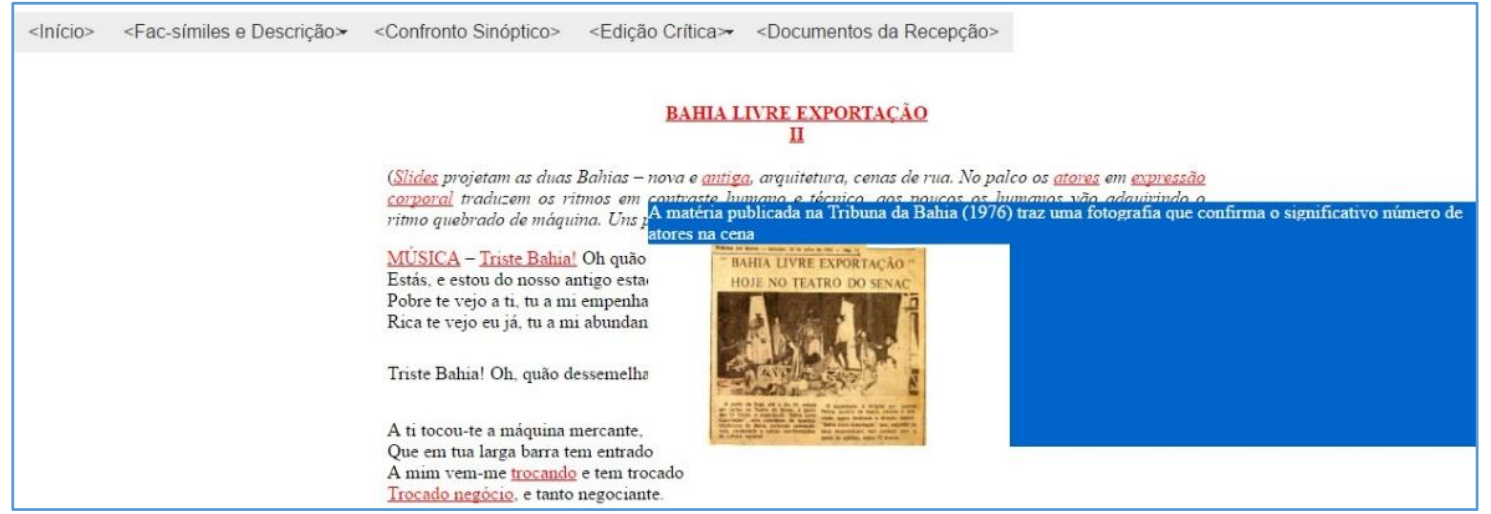

Fonte: Almeida, 2014.

Em se tratando de um espetáculo composto a partir da citação de diversos autores da literatura, como Jorge Amado e Cecília Meireles, e da música brasileira, como Caetano Veloso e Gilberto Gil, o hipertexto permitiu relacionar, por meio do link o trecho citado com o script do espetáculo. Utilizamos esse recurso com a finalidade de permitir a leitura isolada do texto de partida, assim como compará-lo à adaptação feita por Jurema Penna. O leitor pode, portanto, perceber, orientado ou não por notas editoriais, como o dramaturgo aproveitou certo excerto para a composição de uma cena. É possível verificar supressões, acréscimos e retextualizações, bem como vislumbrar deslizamentos e ampliações de sentidos a que cada trecho citado é submetido ao ser amalgamado ao texto do espetáculo.

Tal recurso de composição do texto teatral, no qual se conjugam diversos textos a partir da colagem, é definido por José da Costa Filho (2009) como sendo uma dramaturgia de leitura, compreendendo-a como um recurso do teatro contemporâneo amplamente utilizado. Nesse sentido, a leitura é entendida como procedimento de criação, atividade a partir da qual o indivíduo manipula as produções textuais de uma sociedade para criar seu próprio texto. Este processo de escrita dá origem a um texto composto por fragmentos que, dotados de um senso de continuidade dado pelo escritor, formam um conjunto

O trabalho da citação como operador de intertextualidade (COMPAGNON, 2007) aproxima-se da noção de hiperlink, uma vez que estabelece relações entre o texto enunciado no palco e o repertório cultural e literário do leitor ou espectador, influenciando sua percepção da cena e seu entendimento do espetáculo. Essa escrita fragmentária característica do teatro contemporâneo, que se apropria de outros textos e os faz circular por meio da encenação assemelha-se, portanto, à escrita no plano virtual, caracterizada pela colaboração, capacidade de compartilhamento e apropriação de diferentes textos.

Aludiremos, por fim, ao terceiro aspecto indicado por Cerquiglini (2010) e citado no início dessa seção: os contatos disciplinares entre Crítica Textual e Informática também 
implicam no fim do monopólio livresco e, portanto, produzem impactos já perceptíveis nas possibilidades de circulação dos textos e nos valores atribuídos a eles.

Diferente da publicação dos impressos, a produção textual elaborada para o mundo virtual diminuiu a separação entre a escrita pública e a privada: um upload de um arquivo em um site ou a publicação de um post em um blog são suficientes para colocar um texto em circulação em poucos segundos, independente das instâncias de legitimação do mercado editorial. $\mathrm{O}$ advento da internet, dessa forma, produz alternativas de publicação em detrimento dos restritos âmbitos das editoras.

Nesse sentido, um texto não precisa ser dado como acabado para ser divulgado em meio virtual, abrindo espaço para a colaboração dos leitores no seu processo de construção, visto que a flexibilidade do suporte permite que alterações sejam feitas, sem ocasionar gastos financeiros que seriam impeditivos, em se tratando de livros impressos. Por sua vez, a velocidade da publicação interfere na relação autor-leitor: ao publicar em meio digital, o autor tem um feedback mais rápido em comparação com o impresso, o que pode gerar consequências para a elaboração de novas versões. $O$ ambiente virtual configura-se, assim, como um espaço em que a escrita colaborativa se constitui por excelência.

No entanto, os textos publicados em meio digital recebem ainda um valor distinto dos impressos. Chartier (2002) chama a atenção para os deslocamentos empreendidos à ordem dos discursos pelos textos virtuais, e destaca uma diferença basilar entre a cultura impressa e a cultura digital:

Na cultura impressa, a percepção imediata associa um tipo de objeto, uma classe de textos e usos particulares. A ordem dos discursos é assim estabelecida a partir da materialidade própria de seus suportes: a carta, o jornal, a revista, o livro, o arquivo etc. Isso não acontece mais no mundo digital onde todos os textos, sejam eles quais forem, são entregues à leitura em um mesmo suporte (a tela do computador) e nas mesmas formas (geralmente as que são decididas pelo leitor). É assim criada uma contiguidade que não mais distingue os diferentes gêneros ou repertórios textuais que se tornaram semelhantes em sua aparência e equivalentes em suas autoridades (CHARTIER, 2002, p. 109) ${ }^{12}$.

Considerado fluido, aberto, facilmente modificável, o texto digital é frequentemente associado a uma forma menos importante de publicação. O livro impresso ocuparia o lugar central do mercado editorial, como materialidade privilegiada para a transmissão de um saber, considerado canônico e legítimo, que para alcançar tal forma distinta, foi submetido a um processo de avaliação que garantiria a sua qualidade. Essa visão, que ainda está bastante presente, desconsidera as questões relativas às políticas editoriais, bem como ao uso do meio virtual como suporte para a transmissão de informações fidedignas e factíveis.

Acerca das questões atinentes aos capitais econômico e simbólico mobilizados por esse tipo de publicação, Bellei (2012) chama a atenção para a reprodução, no mundo virtual, de formas de controle e legitimação das publicações constatadas no mundo dos impressos, uma vez que

esse vasto hipertexto conhecido como a internet não existe primariamente para produzir e fazer circular a informação, mas para gerar e fazer circular capital econômico e simbólico. Ou mais precisamente, a rede é o local do acúmulo eletrônico do capital, através do uso adequado da "moeda" da informação e do conhecimento. Toda informação relevante colocada nas malhas da rede é, para todos os efeitos prático, dinheiro. Mais do que uma democracia do conhecimento, a rede é um hipermercado de informação (BELLEI, 2012, p. 12-13).

Como todo produto cultural, devemos compreender a internet como meio de circulação de textos, inserido no modelo capitalista de produção de riquezas, sendo, com

12 Ainda nesse momento da discussão, Chartier destaca como um mal-estar causado pela cultura digital a impossibilidade de hierarquizar os textos pelo seu suporte, prática bastante comum na cultura impressa, em que um livro, somente por se considerar sua materialidade, é mais importante que um bilhete. 
isso, atravessada pelas questões econômicas e ideológicas. Assim, quem tem mais poder econômico e/ou simbólico para disponibilizar conteúdo na internet, também terá mais possibilidades de fazê-los circular, aumentando a capacidade de gerar riquezas. No entanto, a apropriação que os indivíduos fora da lógica do sistema de produção fazem dos suportes digitais, como forma de empoderamento e intervenção em suas realidades, viabiliza a circulação de textos frequentemente excluídos do universo das publicações impressas, visto que

a rede, embora utilizada maciamente pelo capital, pode ser apropriada para outros fins, em virtude de sua natureza enquanto diáspora digital. Quando se atenta para essa natureza diaspórica e dispersiva da rede, torna-se possível utilizá-la precisamente como um antídoto à concentração do capital cultural. É importante, portanto, distinguir entre um certo uso da rede que favorece o capital e um uso que a ele resiste. (BELLEI, 2012, p. 16)

Consideramos, portanto, a publicação de textos teatrais baianos em meio digital uma atitude resistência. Em primeiro lugar, trata-se de um gênero textual que ocupa um escopo muito pequeno do mercado editorial, se comparado a outros gêneros. Além disso há uma tendência a se privilegiar a literatura dramática canônica, ou mesmo uma escrita arraigada ao teatro burguês e à tradição do século XVII e XVIII, que tem por meta a representação de uma vida cotidiana e objetiva construir um script finalizado para ser levado ao palco.

Afasta-se desse modelo um teatro que representa o cotidiano baiano em suas diversas classes sociais, constituído de experimentações de distintas formas dramáticas e que, frequentemente, adquiriam a forma escrita em consequência do protocolo da censura federal. Para além da publicação dos textos a serem lidos ou encenados, as edições em meio digital possibilitam narrar a história desses textos, que registram importantes capítulos das artes cênicas baianas, sendo possível também evidenciar os sujeitos que as constituíram e registrar a circulação dos espetáculos em âmbito local e nacional a partir dos documentos de censura.

É preciso também considerar o grande volume de informações paratextuais que uma edição em meio digital pode disponibilizar acerca do texto editado. Estas informações, além de suplementar a leitura do texto teatral, destacam-se por fornecer uma ampla gama de informações contextuais, transformando a edição em um caminho que permite adentar às representações, ideologias e a própria história da Bahia dos anos 1964-1985.

Acreditamos que estas as edições em suporte digital oportunizam maneiras de experimentar as potencialidades desse suporte, possibilitando a construção de uma experiência de escrita e de leitura assaz diversa daquelas dos textos impressos. Permitem, portanto, a elaboração de novas perspectivas para a publicação de edições científicas que abalam os pilares das categorias dos textos literários impressos e suplantam, em acréscimo, a lógica do mercado editorial.

\section{CONSIDERAÇÕES FINAIS}

Em que pese se tratar de uma área de estudos emergente, as Humanidade Digitais já têm fornecido subsídios teórico-metodológicos para o desenvolvimento das relações transdisciplinares entre Crítica Textual e Informática. Veja-se o avanço das reflexões acerca da cultura escrita em suporte digital, as ampliações na noção de texto, materializadas no hipertexto, e o desenvolvimento e aperfeiçoamento de ferramentas informáticas para a edição. Esta interface disciplinar, que se encontra em franco desenvolvimento em centros de pesquisa no âmbito nacional e internacional, mostra-se especialmente interessante para a edição de textos teatrais censurados.

Por se tratar de um texto em que atualizações são realizadas a cada encenação, gerando diferentes versões, a flexibilidade do suporte digital e seus recursos de múltiplas janelas, pop- 
ups, mouseover e tooltip destacam-se como ferramentas adequadas à representação dessa dinâmica textual, em oposição à rigidez estática do suporte papel. Acreditamos, portanto, que tal interface tem promovido atualizações nas concepções e metodologias de edição para os textos teatrais censurados, resultando em edições adequadas à multiplicidade e multimodalidade do referido objeto de estudo, bem como às propostas da edição de textos na contemporaneidade, cujo foco não recai apenas sobre o texto final, mas desloca-se para compreender os processos de elaboração, transmissão, circulação e recepção, tornando-os visíveis no texto editado.

\section{REFERÊNCIAS}

ALMEIDA, Isabela Santos de. A crítica filológica nas tessituras digitais: arquivo hipertextual e edição de textos teatrais de Jurema Penna. f. 320 Il. 2014. Tese (Doutorado) - Instituto de Letras, Programa de Pós-graduação em Literatura e Cultura, Universidade Federal da Bahia, Salvador, 2014. 2 v. [Impresso + Recurso digital].

BAHIA livre exportação" hoje no teatro do SENAC. Tribuna da Babia, Salvador, 22 jul. 1975, p.11.

BELLEI, Sérgio Luiz Prado. Hipertexto e literatura. Porto Alegre: EDIPUCRS, 2012.

BOLTER, Jay David. Writing space: computers, hypertext, and the remediation print. 2. ed. Mahwah: Lawrence Erlbaum, 2001.

BORGES, R.; SOUZA, A. S. de;. Filologia e edição de texto In: BORGES, R.; SOUZA, A. S. de; MATOS, E. S. D. de; ALMEIDA, I. S. de Edição de texto e crítica filológica. Salvador: Quarteto, 2012. p. 15-59.

CAMBRAIA, César Nardelli. Introdução à crítica textual. São Paulo: Martins Fontes, 2005.

CERQUIGLINI, Bernard. Une nouvelle philologie. In: PHILOLOGIE A L'ERE DE L'INTERNET, 2000, Budapeste. Disponível em: < http://magyarirodalom.elte.hu/colloquia/000601/cerq.htm>. Acesso em: 26 dez. 2016.

CHARTIER, Roger. Os desafios da escrita. Tradução Fulvia M.L. Moretto. São Paulo: Unesp, 2002.

CHARTIER, Roger. Un humanista entre dos mundos: Don McKenzie. In: MCKENZIE, D. F. Bibliografía y sociologia de los textos. Traducción Fernando Bouza. Madrid: Akal Ediciones, 2005.

COLLATEX. Software for Collating Textual Sources. Disponível em: < http://collatex.net/> Acesso em: 26 dez. 2016.

COMPAGNON, Antoine. O trabalho da citação. Tradução Cleonice P. B. Mourão. Belo Horizonte: UFMG, 2007.

COSTA FILHO, José da. Teatro contemporâneo no Brasil. Rio de Janeiro: 7 Letras, 2009.

DUÉ, Casey; EBBOTT, Mary. Digital criticism: editorial standards for the Homer multitext. Changing the Center of Gravity: Transforming Classical Studies Through Cyberinfrastructure. v.3, n. 1, 2009.

Disponível

em: 
< http://www.digitalhumanities.org/dhq/vol/003/1/000029/000029.html>. Acesso em 26 dez. 2016.

JUXTA COMMONS. Disponível em: <http://juxtacommons.org/home/index>. Acesso em: 26 dez. 2016.

LOURENÇO, Isabel Maria da Graça. The William Blake Archive: da gravura iluminada à edição electrónica. 2009. Tese (Doutorado em Letras) - Faculdade de Letras da Universidade de Coimbra, Programa de Pós-Graduação em Língua e literaturas Modernas, Coimbra. Disponível em: < https://estudogeral.sib.uc.pt/handle/10316/12069>. Acesso em: 26 dez. 2016.

MANIFESTO for the digital humanities, 2010.Disponível em: <http://tcp.hypotheses.org/files/2010/07/Pages-de-Aff_Dh40x60-EN2BIS.pdf > . Acesso em 26 dez. 2016.

MCGANN, Jerome. The rationale of HyperText. 1995. Disponível em: < http://www2.iath.virginia.edu/public/jjm2f/rationale.html>. Acesso em: 26 dez. 2016.

MCKENZIE, D. F. Bibliografía y sociologia de los textos. Traducción Fernando Bouza. Madrid: Akal Ediciones, 2005.

MORRÁS, María. Informática y crítica textual: realidad y deseos. In: VEGA, María José (Coord.). Literatura hipertextual y teoria literária. La Rioja: Mare Nostrum Comunicación, 2003. p. 225-240. Disponível em: < $<$ https://www.academia.edu/678820/Informatica_y_critica_textual_realidades_y_deseos >. Acesso em: 26. dez 2016.

PAIXÃO DE SOUSA, Maria Clara. Conceito material de um "texto digital". Texto Digital, Florianópolis, v. 5, n. 2, dez. 2009, p. 159-187. Disponível em: < https://periodicos.ufsc.br/index.php/textodigital/issue/view/1429>. Acesso em: 26 dez. 2016.

PENNA, Jurema. Bahia Livre Exportação. In: ALMEIDA, Isabela Santos de. A crítica filológica nas tessituras digitais: arquivo hipertextual e edição de textos teatrais de Jurema Penna. f. 320 Il. 2014. Tese (Doutorado) - Instituto de Letras, Programa de Pós-graduação em Literatura e Cultura, Universidade Federal da Bahia, Salvador, 2014. 2 v. [Impresso + Recurso digital].

PINTO, P. R. M. A lógica contemporânea e a transdiciplinaridade. In: DOMINGES, I. (Org.). Conhecimento e transdisciplinaridade II: aspectos metodológicos. Belo Horizonte: Editora UFMG, 2005. p.137-167.

PORTELA, M. Livros iluminados digitais: autógrafo e reprodução em The William Blake Archive. Literatura, cultura e outras artes. Letras / Universidade Federal de Santa Maria. Centro de Artes e Letras. Programa de Pós-graduação em Letras. Santa Maria, v.25, n. 51, jul./dez. 2015.

SANTOS, Rosa Borges dos. Edição e estudo de textos teatrais censurados na Babia: a Filologia em diálogo com a Literatura, a História e o Teatro. Salvador: EDUFBA, 2012.

THE SILENT history. <http://www.thesilenthistory.com/what>. Acesso em 26 dez. 2016. 
ISSN $1415-8973$

VERSIONING Machine Disponível em: < http://v-machine.org/ >. Acesso em: 26 dez. 2016. 